\title{
REPORT ON THE XIX INTERNATIONAL CONFERENCE "PANDEMIC AND GOVERNANCE - TOWARDS AN APPROXIMATION OF COVID-19's LEGAL, ADMINISTRATIVE, FISCAL AND POLITICAL DILEMMAS" (5-6 NOVEMBER 2020, BUDAPEST, HUNGARY)
}

On $5^{\text {th }}$ and $6^{\text {th }}$ November 2020, in joint cooperation of the Faculty of Public Governance and International Studies of the University of Public Service in Budapest and the Center for Public Finance of Central and Eastern Europe (CPFCEE), Faculty of Law of the University in Bialystok, an international conference was held, entitled: Pandemic and Governance - Towards an Approximation of Covid-19's Legal, Administrative, Fiscal and Political Dilemmas. As part of the conference, on the second conference day also PhD students and young scientists' seminar was organized. The conference had both English and Russian panel.

The conference was organized due to the global outbreak of a new coronavirus, COVID-19. In order to slow down the spread of the disease governments throughout the world introduced a variety of regulations from several forms of social distancing to provisional quarantine. These measures turned normal state operations completely upside down, affecting several segments and aspects of governance, local administration, residential liberties, fiscal policies and national and global politics at large. Key research areas are the trends and changes in legal and administrative solutions regarding the changes in public financing and fiscal models in connection with the pandemic.

In line with the expectations of the organizers, the conference provided a scientific forum for the participants of the event, consolidating in all respects heterogeneous academic environment and presenting an interdisciplinary approach. The interdisciplinary and heterogeneous nature of the conference is well illustrated by the diverse origin of participants and multiplicity of issues examined: in addition to the EU issues, considerations on the Middle East and Russia and the disciplinary attachment of speakers: from public finance and fiscal theories to government ethics, up to decision and game theory, various governance theory and public finance issues related to the coronavirus have been addressed. It was a special pleasure for the organizers that doctoral students were able to discuss their theses with professors from renowned research institutions. 


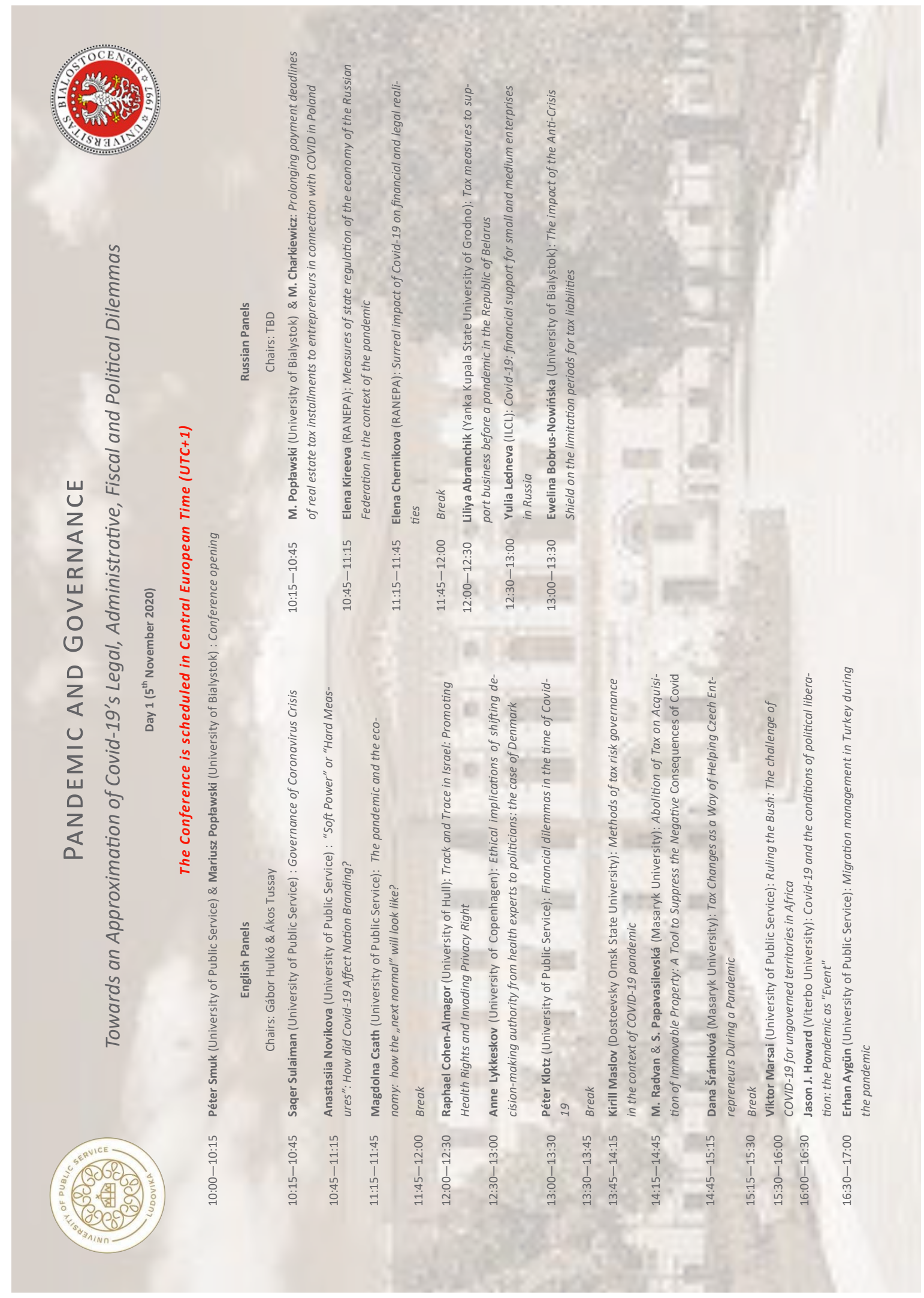




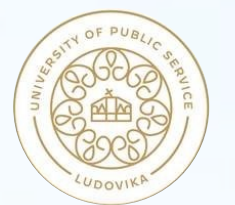

\section{PANDEMIC AND GOVERNANCE}

\section{Towards an Approximation of Covid-19's Legal, Administrative, Fiscal and Political Dilemmas \\ Day 2 (6 $6^{\text {th }}$ November 2020)}

The Conference is scheduled in Central European Time (UTC+1)

10:00-10:15 Mariusz Popławski (University of Bialystok): conference opening

10:15-10:35 A. Popovič \& L. Hrabčák (Pavol Jozef Šafárik University): Post COVID-19 world and potential compensatory tax instruments in the context of the digital economy

10:35-10:55 Ekaterina Kosiuk (University of Public Service): Impact of COVID-19 on Civil and Political Rights

10:55-11:15 Natália Antušová (Pavol Jozef Šafárik University): Taxable person as an element of an European digital services tax

11:15-11:30 Break

11:30-11:50 Sofian Bouhlel (University of Public Service): Role of the Hungarian Local Governance in Responding to COVID-19 Crisis

11:50-12:10 Ekaterina Popova (University of Public Service): The Urge of Vaccine: COVID-19, Immigrants and Nationalism in Hungary

12:10-12:30 Jiří Kappel (Masaryk University): Impact of Pandemic in Context of the Czech Interest Deductibility Limitation Rules

12:30-12:50 Anna Urbanovics (University of Public Service): Communication of Covid-19 in the Mediterranean region - a social media content analysis

12:50-13:05 Break

$13: 05-13: 25$

$13: 25-13: 45$

$13: 45-14: 05$

Monika Stojáková (Pavol Jozef Šafárik University): Covid-19 and the "Digital Services Tax" : Loss of Political Attention?

Ola Majthoub (University of Public Service): Navigating the Way Forward and Survive the Crisis

Jozef Sábo (Pavol Jozef Šafárik University): Taxation of robots: back to the future?

14:05-14:25 Viktória L. Pató (University of Public Service): New paths of digital policies as a positive effect of the COVID-19 pandemic in the European Union 